\title{
ICF perspectives in the context of Giftedness
}

\author{
Authors: André de Souza Rocha1; Ananda Ludwig Burin²; Aline Mendes³
}

1. Physical therapist, Rehabilitation Center - CENER/ Research developer, Center of studies and research - NESPE. Santa Catarina Foundation of Special Education - FCEE http://lattes.cnpq.br/2661547964572512

2. Mathematician, Center of Giftedness - NAAH/S. Santa Catarina Foundation of Special Education - FCEE

http://lattes.cnpq.br/3927288556773114

3. Psychologist, Center of Giftedness - NAAH/S. Santa Catarina Foundation of Special Education - FCEE

http://lattes.cnpq.br/9369228158874271

\section{Editorial}

The International Classification of Functioning, Disability and Health (ICF) is a framework for organizing and documenting information on functioning and disability ${ }^{1}$. It conceptualizes functioning as a "dynamic interaction between a person's health condition, environmental factors and personal factors" through a biopsychosocial model, relevant for obtaining indicators on human functioning ${ }^{2}$. Since its publication by the World Health Organization - WHO in $2001^{1}$ and its translation into Portuguese in $2003^{3}$, several public policy initiatives have been guiding its usage in health, social assistance and education systems, both nationally and internationally ${ }^{4-7}$. With the appropriation and study of its concepts in the field of education, new perspectives of application and possibilities for updating the ICF emerge. In this sense, the functioning of Gifted children represents a challenge for the ICF, once the biopsychosocial model presented does not seem to meet, or even contemplate, levels of functioning above the assumed standard for the general population. This editorial will discuss the possibilities of ICF application when analyzing the functioning of children and youth with Giftedness and will present a proposal to expand the qualifiers so as to encompass this context.

As stated by Renzulli ${ }^{8,9}$ e Smedsrud ${ }^{10}$, the expanded concept of giftedness goes beyond the higher intelligence and addresses the outstanding talent in a perspective more in line with the individual's high functional competencies. This concept describes people who show heightened potential in any of the following areas, either isolated or combined: intellectual, academic, leadership, psychomotor skills and arts, in addition to presenting with great creativity, learning engagement, and task-performance skills in topics of interest ${ }^{8-11}$.

Thus, gifted individuals are those who have significantly higher skills in one or more knowledge areas, when compared to their peers in the same domain of capability and interest, in addition to performing tasks with ease of learning, creative thinking and curiosity, within their area of interest ${ }^{8-10}$. Data from WHO estimate that 3.5 to $5 \%$ of the world population score higher on traditional IQ tests, which represents only gifted people in one or more academic areas ${ }^{12}$. As we include other knowledge areas such as leadership, psychomotor skills and the arts, this proportion significantly increases up to 15 to $30 \%$ of the world population ${ }^{11}$.

This marked number of people would not currently receive any appropriate analysis of their high functioning when considering the qualifier structure proposed in the ICF. Qualifiers in the 
components of functioning and disability only indicate the preservation or loss of a given health construct. Consequently, the ICF-based functioning of people with signs of giftedness may not be compatible with their actual level since their ability is above the description the qualifiers are able to identify. Given the way the qualifier is proposed, on a negative scale, there is no predictability of above-average functioning.

Objectively, the chapters on Mental Functions (b1) and Learning and applying knowledge (d1) would be the main starting points for coding talented children and young people. However, as discussed earlier, the qualification process for these codes currently only allows for pointing out the "loss" of health. In this way, within the scope of giftedness, it could be applied the same positive concept regarding the Environmental Factors qualifiers, which allow specifying whether aspects of the environment act as facilitators (e+, positive scale) or barriers (e., negative scale). The ICF itself in its Annex 2 describes that "at the user's discretion coding scales can be developed to capture the positive aspects of functioning" 1 . Therefore, the qualifiers could be reported similarly to the scale of facilitators, adapting the labels according to the coded component: $\mathbf{x x x + 0}$ No problem/limitation in function/capacity (0-4\%); $\mathbf{x x x + 1}$ slightly high function/capacity (5-24\%); moderately high function/capacity (25-49\%); $\mathbf{x x x + 3}$ Considerably high function/capacity (50-95\%); $\mathbf{x x x + 4}$ Completely high function/capacity (96-100\%); xxx+8 high function/capacity, not specified.

The possibility of expanding this model of using positive qualifiers for the codes of Mental Functions (b1) and Learning and knowledge application (d1), would permit the description of the high capacity, creativity and leadership in one or more areas of these individual's functioning. For example, a child able to Learn to calculate (d150) or Calculate (d172) in significantly less time compared to their peers (most children has performed these activities in 60 minutes, while the child has done it in 10 minutes, less than half of the time taken by the others) would be coded just as d150.0 and d172.0 (both no limitations). However, the child has, indeed, an above-average ability to perform these mathematical reasoning and execution activities. This talent would certainly impact assessments covering Intellectual functions (b117) and Calculation Functions (b172). As a result, if there was the positive coding alternative, this child could receive codes $d 150+4$ and $d 172+4$ (both completely high capacity), in other words, a capacity up to $100 \%$ above the average for these activities, according to the quantitative option of qualifiers. Furthermore, Mental functions (b1) codes could also be qualified positively, even in the absence of a standardized test (eg b117+8 and b172+8, high function not specified).

Within the same scope, when we analyze, in the light of the ICF standards so far, the functioning of children with high motor skills and talent to execute movements at a much higher capacity compared to their peers, they would be qualified in their Psychomotor functions just as $b 147.0$ (no problem) and in their capacity to Acquire skills just as $d 155.0$ (no limitation). Once again, the qualifiers upgrade to a positive scale likewise the Environmental Factors chapters, would allow for a coding more coherent with these children's actual functioning, for example b147+8 (high function, not specified) and $d 155+4$ (completely high capacity). The latter in cases where the motor skill tests have demonstrated a capacity $100 \%$ higher compared to others of the same age and sex.

As stated previously, the domains of creativity and leadership are important components in analyzing the performance of activities which may indicate whether a child or young person has a distinguished talent 8,9 . The ability to play a musical instrument brings about aspects of functioning that could also be described through the ICF background, by adopting the same rationale of the positive scale set in the Environmental Factors qualifier. In this case, the ability would be reported in the context of Mental functions of sequencing complex movements (b176) related to Acquisition of skills (d155) to play a given instrument (Art and culture - d9202). Children who show remarkable mastery of these components by being able to learn to play the instrument far beyond the expected, 
would be more likely to have codes varying from $d 155+8$ to $d 155+4$ instead of simply receiving d155.0 (no limitation in acquiring skills). This same reasoning could be applied to behaviors that indicate a higher capacity for leadership, as in the activities of Making decisions (d177+8) and Handling stress and other psychological demands (d240+8), for example.

Another relevant issue to be debated involves the perspective of twice-exceptional children. It includes individuals who have a disability/disorder while also being identified as gifted/talented in one or more areas. Specifically, they have superior capacity in some area of human performance concomitant with other conditions such as: dyslexia, dysgraphia, psychiatric disorders, physical and sensory disabilities, central processing deficit, attention deficit hyperactivity disorder (ADHD), autism spectrum disorder (ASD) ${ }^{13,14}$. In this scenario, it is possible for a child with ASD to have a restriction in Basic interpersonal interactions (d710.8) as well as be able to focus a great deal of attention to a calculus exercise in a far superior way compared to other children (Concentrate attention - d160 and Calculate - d172). The possibility of applying a positive qualifier to these Activity and Participation components, would allow identifying the twice-exceptionality in these children $(d 160+8$ and $d 172+8$ ), otherwise only the absence of limitation could be qualified (d160.0 and $d 172.0$ ).

Given the above, the discussion on the possibility of expanding the scope of the ICF to include the high functioning of giftedness is of great relevance. The process of inserting positive qualifiers may enable the ICF usage as a screening or follow-up tool for children with signs of precocity or giftedness, eligible for further evaluation. According to the several application examples discussed in this editorial, the proposal to incorporate to the biopsychosocial model the positive qualifiers, expanding them to other ICF components in addition to the Environmental Factors, has a great potential to guide referrals to programs that can properly assess the singular characteristics of gifted people. This action will provide these children and youth with more effective educational and health services. The early identification of high functioning, translated into a remarkable talent, has a positive impact on the future of these children who will be able to contribute to society by playing outstanding roles as scholars, researchers, high-performance athletes, recognized artists and entrepreneurial and social leaders ${ }^{9}$.

Conforming to the ICF Annexes 7 and $8{ }^{1}$, the classification is under constant improvement and review and the proposal introduced here aims to contribute to this process, bringing to light the debate on high functioning. Moreover, the initiative to give greater coverage to the ICF, allowing specifically analyzing the characteristics of gifted people, will encourage its use in the educational scenario and add application possibilities, mainly in the field of special education. 


\section{References}

1. WHO. International Classification of Functioning, Disability and Health. Geneva: World Health Organization, 2001.

2. WHO. How to use the ICF: A practical manual for using the International Classification of Functioning, Disability and Health (ICF). Exposure draft for comment. Geneva: World Health Organization, 2013.

3. Organização Mundial da Saúde. Classificação Internacional de Funcionalidade, Incapacidade e Saúde. OMS - OPAS e Ed da Univ São Paulo 2004; 238.

4. Brasil. Lei 13.146, de 6 de julho de 2015. Institui a Lei Brasileira de Inclusão das Pessoas com Deficiência (Estatuto da Pessoa com Deficiência). Diário Oficial da União 2015; 7 jul., http://www.planalto.gov.br/ccivil_03/_ato2015-2018/2015/lei//13146.htm (2015, accessed 18 December 2019).

5. Castro S, Palikara O. An Emerging Approach for Education and Care: Implementing a Worldwide Classification of Functioning and Disability Edited. New York: Routledge, 2018. Epub ahead of print 2018. DOI: 10.4324/9781315519692.

6. De Miranda-Correia L. Special education in Portugal: The new law and the ICF-CY. Procedia - Soc Behav Sci 2010; 9: 1062-1068.

7. Hollenweger J. Development of an ICF-based eligibility procedure for education in Switzerland. BMC Public Health 2011; 11: S7.

8. Renzulli JS. The three-ring conception of giftedness: A developmental model for promoting creative productivity. 2005. Epub ahead of print 2005. DOI: 10.1017/CBO9780511610455.015.

9. Renzulli JS. Reexamining the Role of Gifted Education and Talent Development for the 21st Century: A Four-Part Theoretical Approach. Gift Child Q 2012; 56: 150-159.

10. Smedsrud J. Explaining the variations of definitions in gifted education. Nord Stud Educ 2020; 40: 79-97.

11. Virgolim AMR. Altas habilidade/superdotação: encorajando potenciais. Brasilia: Ministério da Educação, Secretaria de Educação Espeial, 2007.

12. Pérez SGPB. Mitos e Crenças sobre as Pessoas com Altas Habilidades: alguns aspectos que dificultam o seu atendimento. Revista Educação Especial 2003; 1: 45-59.

13. Roama-Alves RJ, Nakano T de C. Dupla excepcionalidade: Altas habilidades/Superdotação nos transtornos neuropsiquiátricos e deficiências. SãoPaulo: Vetor, 2021.

14. Ronksley-Pavia M. A Model of Twice-Exceptionality. J Educ Gift 2015; 38: 318-340. 